\title{
POLÍTICAS PÚBLICAS E CAPITAL SOCIAL EM DUAS CIDADES LATINO-AMERICANAS
}

\author{
Sonia Santos \\ Everton Santos \\ Cristina Ennes \\ Valdir Pedde
}

\begin{abstract}
Resumo
Este artigo tem como objetivo principal compreender os impactos do capital social e das instituições no desempenho das estruturas do Estado e, consequentemente, de suas políticas públicas em duas cidades latino-americanas: Porto Alegre e Montevidéu. O trabalho tem como pressuposto teórico o fato de que a sinergia entre instituições e o capital social são variáveis que influenciam na eficiência dos serviços públicos oferecidos e de suas políticas. Para tanto, a partir da revisão da bibliografia especializada, bem como de pesquisa quantitativa (banco de dados Nupesal/UFRGS) e pesquisa documental feita, com os orçamentos públicos de ambas as cidades e entrevistas semiestruturadas com gestores, buscou-se demonstrar que o capital social, aliado às instituições formais, pode proporcionar uma melhora dos serviços prestados pelo Estado.
\end{abstract}

Palavras-chave: Capital Social; Porto Alegre; Montevidéu; Confiança Institucional.

\begin{abstract}
The main objective of the thesis is to deepen the understanding of the influence of social capital and institutions in the performance of public government structures in two Latin-American cities: Porto Alegre and Montevideo. The work develops the hypothesis that the synergy between the institutions and the social capital increases the effectiveness of the public policy. Thus, through review of specialized bibliography, the analysis of quantitative research NUPESAL/UFRGS, the conduct of documentary research using public budget documents, and semi structured interviews with local government employees an attempt was made to demonstrate that high levels of Social Capital and the existence of formal institutions can improve the effectiveness of public services.
\end{abstract}

Keywords: Social Capital; Porto Alegre; Montevideo; Institutional Reliability.

\section{Introdução}

Desde as últimas três décadas do final século $X X$, os países da América Latina experimentam um período de normalidade democrática, substituindo regimes militares de soluções autoritárias por regimes civis, que encontram na democracia uma possibilidade de equacionamento dos problemas contemporâneos. Ao mesmo tempo, sob os efeitos contraditórios da globalização econômica, do controle da inflação e da dívida externa, abre-se 
um novo cenário desafiador à eficiência do Estado no enfrentamento às questões sociais que se impõem historicamente aos diferentes governos da região.

A democracia coexistindo com condições de pobreza, desigualdade e exclusão social é uma questão que desafia cientistas políticos e governos locais para buscar aferir o grau de eficiência das estruturas do Estado, bem como de suas políticas públicas. Este trabalho tem a pretensão de contribuir para a compreensão deste fenômeno em tela, no sentido de ajudar a pensar nas possibilidades da diminuição das desigualdades que caracterizam esses países e essas cidades.

O Banco Mundial e a Comissão Econômica para a América Latina e o Caribe/ONU (CEPAL, 2008), por exemplo, assinalam que, muito embora haja avanços em várias áreas na América Latina, a exclusão social e a disparidade entre ricos e pobres se acentuaram seriamente nas últimas décadas no continente. Sob essas condições, o funcionamento e a estabilidade das instituições e a percepção das pessoas sobre o desempenho do Estado e de suas políticas ganham peso na análise do nível de desenvolvimento econômico e social obtido.

Já há um certo consenso nas ciências sociais de que a política econômica por si só (recursos orçamentários) não é suficientemente capaz de garantir uma sociedade com equidade. Assim, o conceito de capital social surge como fator considerável nos processos que visem a melhorar as condições de vida dessas populações. O capital social, aqui sumariamente falando, é entendido na esteira de Putnam (2005), como laços de confiança interpessoais, em uma determinada sociedade que, aliados ao desempenho das instituições, podem ter efeitos positivos sobre as políticas públicas, ou seja, podem melhorar a capacidade dos governos em atenderem às demandas da população, melhorando a educação, a saúde e o bem-estar em diferentes regiões do mundo.

Por outro lado, as instituições formais guardam papel importante como indutoras do desenvolvimento econômico, de acordo com a bibliografia especializada.

Com o propósito de avançarmos a compreensão sobre os fenômenos que envolvem a complexa relação entre Estado e sociedade na América Latina, este artigo tem como problema de pesquisa investigar comparativamente, a partir de duas cidades latinas, Montevidéu no Uruguai e Porto Alegre no Brasil, a influência que a cultura política, aliada aos regramentos institucionais formais, exerce sinergeticamente sobre 0 desempenho das instituições dos governos locais e, portanto, de suas políticas públicas ${ }^{1}$. Em outras palavras, busca-se compreender em que medida a

\footnotetext{
1 Cabe ressaltar que estamos comparando duas cidades latinas, Montevidéu, capital de um Estado Unitário (Uruguai) e Porto Alegre, capital de um Estado Federado (Brasil). Esta observação será retomada adiante quando referirmos as implicações orçamentárias.
} 
confiança interpessoal (o capital social), aliada às ações públicas de gestores, notadamente no que diz respeito aos recursos orçamentários, impacta satisfatoriamente sobre os serviços prestados às duas populações.

Para melhor compreender a realidade que nos é posta, buscamos amparo teórico em duas correntes das ciências sociais, quais sejam: a culturalista e a neoinstitucionalista. A primeira com foco em práticas sociais, normas e relações de confiança entre cidadãos, e a segunda com ênfase nas instituições - sua formação, importância e eficiência.

A metodologia utiliza dados quantitativos para explicar o resultado de políticas públicas. Os dados utilizados são oriundos de pesquisa quantitativa, tipo survey realizada pelo Núcleo de Pesquisas sobre a América Latina da Universidade Federal do Rio Grande do Sul (NUPESAL/UFRGS em 2005, banco de dados). Com a ajuda do programa Statistical Package for the Social Sciences (SPSS), esses dados foram analisados, cruzados e testados. Para cotejarmos os dados quantitativos do survey, recorremos à pesquisa documental sobre os orçamentos públicos das cidades pesquisadas, procurando verificar seu impacto na percepção dos cidadãos.

Este artigo está dividido em dois tópicos. O primeiro, Culturalismo e Institucionalismo: Sinergismo Teórico, fundamenta teoricamente o estudo com base nos autores da bibliografia especializada, salientando a bifurcação epistêmica entre institucionalistas e culturalistas, para, logo em seguida, sublinhar sua possibilidade de convergências. O segundo, intitulado Capital Social e Instituições: Sinergismo Empírico, constitui-se na análise do banco de dados e dos orçamentos públicos, demonstrando o mútuo impacto entre cultura e instituições. Foram escolhidos para avaliação da satisfação da população de Porto Alegre e Montevidéu os serviços de educação, saúde e segurança, assim como os recursos destinados a cada uma dessas áreas em seus respectivos orçamentos.

\section{Culturalismo e Institucionalismo: Sinergismo Teórico}

Que fatores podem estar determinando o melhor ou pior desempenho do Estado? Que fatores podem facilitar as ações governamentais, suas políticas? A eficiência de um governo depende de suas instituições ou da qualidade de seus cidadãos (cultura política)? Quais são os pressupostos indispensáveis para que a democracia responda aos desafios contemporâneos?

Procuraremos, neste tópico, demonstrar a convergência possível entre cultura política e instituições.

O conceito de cultura política tem suas sabidas raízes nos estudos de Almond e Verba (1989), referindo-se às atitudes e orientações dos cidadãos voltadas para o sistema político. Com a abertura percebida para a nova presença dos homens comuns nos círculos de controle de poder, esses autores identificam que há uma busca crescente pela ocupação deste espaço 
disputado na arena política, que se amplia no ambiente democrático para segmentos populares que estavam politicamente excluídos.

Diferenciando os aspectos referentes à orientação e atitudes políticas das atitudes não-políticas e culturais, Almond e Verba (1989) vislumbram um vasto campo para aplicação de estudos de abordagem conceitual antropológica, sociológica e psicológica, com o fim de compreender a evolução do movimento de cultura política que se desenvolve.

\begin{abstract}
Na esteira dessa tradição, Robert Putnam (2005) analisou 20 anos da história política, social e econômica da Itália, demonstrando que esse país apresenta grandes diferenças de desenvolvimento regionais, o norte moderno e capitalista industrial, e o sul sob anacrônicos sistemas produtivos agrícolas tradicionais. Essas diferenças, Putnam (2005) observou, existem igualmente na estrutura social das comunidades de cada região e atuam como fatores extraeconômicos que afetam os níveis de desenvolvimento, como destacam Sen e Kliksberg: Las investigaciones pioneras de Robert Putnam, de la Universidad de Harvard, y de James Coleman mostraron que hay distintos factores extraeconómicos que pesan fuertemente en el desempeño de los países en términos de progreso económico y tecnológico, y en la sustentabilidad del desarrollo (SEN e KLIKSBERG, 2007, p. 265).
\end{abstract}

Sen e Kliksberg (2007) ressaltam quatro componentes na definição de capital social: a influência da confiança nas relações entre as pessoas; a capacidade de se associar em cooperação; a consciência cívica; e os valores éticos.

A observação de Putnam (2005) viu que a confiança, a cooperação e os espaços de participação social entre o Estado e a Sociedade são elementos positivos essenciais para o bom funcionamento das instituições políticas. No seu estudo, a cultura política em seu potencial cívico é variável independente, enquanto o desenvolvimento econômico e o desempenho institucional entram como variáveis dependentes. Isso levou à conclusão de que as possibilidades de desenvolvimento socioeconômico de uma comunidade podem depender menos de seu potencial socioeconômico inicial do que do seu potencial cívico.

Observando a importância do culturalismo para a formação e desenvolvimento da sociedade e o funcionamento de suas instituições, temos, também, que considerar a influência da matriz neoinstitucionalista e como as instituições afetam o comportamento dos indivíduos em sociedade.

A corrente neoinstitucionalista não se constitui una, mas se apresenta, pelo menos, em três distintas derivações enquanto métodos de análise, a saber: histórica, de escolha racional e sociológica. Todas procuram compreender as formas de produção de poder, tal como identificadas por 
Hall e Taylor (2003), que apontam a busca para elucidar o papel desempenhado pelas instituições na determinação de resultados sociais e políticos.

Segundo esses autores, o institucionalismo histórico trata da função das instituições como modelos morais e cognitivos a serem seguidos, que permitem a interpretação da ação de um conjunto social, focando, mais diretamente, na questão da distribuição desigual do poder e dos recursos, observando o seguinte: como as instituições afetam o comportamento dos indivíduos; a importância atribuída ao poder e às relações assimétricas de poder; e outros possíveis fatores explicativos, como o desenvolvimento socioeconômico e a difusão de ideias.

O institucionalismo de escolha racional entende que a redução dos custos de transação ligados ao fato de empreender uma atividade acaba moldando o funcionamento das instituições. Essa escola constitui-se na menos sintética das variantes institucionais, havendo, entretanto, pontos comuns: pressupostos comportamentais; a dificuldade de haver arranjos institucionais por conta dos diversos dilemas de ação coletiva que levam a resultados abaixo do esperado; ênfase no papel da interação estratégica na determinação das situações políticas; e busca de explicação para a origem das instituições.

O institucionalismo sociológico, por sua vez, agrega formas e procedimentos como práticas culturais, comparáveis aos mitos e às cerimônias elaborados por numerosas sociedades. Essas práticas seriam incorporadas às organizações, não necessariamente porque aumentam sua eficácia, mas em consequência do mesmo tipo de processo de transmissão que dá origem às práticas culturais em geral. Ele possui características específicas, como a tendência a definir instituições de maneira mais global, como a cultura, por exemplo.

Dentre os autores que professam a importância do neoinstitucionalismo na leitura dos fenômenos sociais e econômicos, North (2007) destaca-se como importante pensador da corrente sociológica e, portanto, mais próxima de nossa perspectiva culturalista. Da construção de sua tese sobre a relevância dos aspectos institucionais do bom funcionamento, do regramento e das relações sociais e econômicas, o autor argumenta que as instituições de fato reduzem a incerteza

[...] ao trazer uma estrutura para o cotidiano. São um guia para a interação humana, de modo que quando queremos cumprimentar amigos na rua, dirigir um carro, $[\ldots]$ ou seja o que for, nós sabemos (ou podemos aprender facilmente) 
como fazer estas tarefas (NORTH, 2007, p. 3, tradução nossa $)^{2}$.

A despeito das divergências entre as correntes, o que foge aos objetivos deste artigo, o conceito de institucionalismo é entendido aqui como a forma vertical de relação entre o Estado e a sociedade civil, na qual o ordenamento jurídico, as normas, as leis e as dotações orçamentárias são prerrogativas e iniciativas do Estado para o desempenho institucional.

Já a variável culturalista é entendida como a relação horizontal existente em uma sociedade, na qual os níveis de confiança e as formas de participação societais nos processos decisórios governamentais compõem um cenário positivo para um bom desempenho institucional e, consequentemente, de suas políticas públicas.

No cotejo do institucionalismo e da cultura política, Santos e Ferreira (2007) entendem que seria um equívoco epistêmico dar primazia a uma variável em detrimento da outra para entender o desempenho do Estado e de suas políticas. Putnam (2005) concluiu que na reforma institucional ocorrida na Itália, por exemplo, as instituições não deixam, também, de ter uma importância fundamental para o próprio desempenho dos governos e o desenvolvimento da sociedade como um todo.

$\mathrm{Na}$ impossibilidade de se estabelecer uma estrutura causal sobre o desempenho dos governos, pois nem a variável instituição tampouco a variável cultura política são determinantes exclusivas, o trabalho entende irrelevante identificar o que é endógeno ou exógeno, ou o que determina o quê no desempenho dos governos (SANTOS e FERREIRA, 2007). O que interessa é a identificação dos impactos recíprocos dessas variáveis na sociedade, em um modelo que combine um sinergismo possível entre as influências da ação das instituições e da cultura política.

A importância da interação dos aspectos culturais dos institucionais e sua influência sobre as estruturas socioeconômicas e das políticas públicas são cada vez mais imprescindíveis para compreendermos os processos de desenvolvimento que podem levar à inclusão social na América Latina.

\section{Capital Social e Instituições: Sinergismo Empírico}

Vistos em linhas gerais os aspectos teóricos deste sinergismo entre instituições e cultura, passamos agora a incursionar pelo campo de pesquisa, procurando demonstrar o sinergismo empírico em nossa investigação.

\footnotetext{
2 No original: "Institutions reduce uncertainty by providing a structure to everyday life. They are a guide to human interaction, so that when we wish to greet friends on the street, drive an automobile, buy oranges, borrow money, form a business, bury our dead, or whatever, we know (or can learn easily) how to perform these tasks".
} 
Sabe-se que o conceito de capital social vem ganhando espaço em estudos prospectivos de processos de desequilíbrio social e econômico em comunidades. Embora não haja unanimidade quanto ao conceito propriamente dito de capital social, há concordância sobre alguns de seus elementos constitutores como redes de relações sociais, estoques de relações, níveis de confiança interpessoal e institucional, dentre outros. Há a defesa de que também sejam integrantes da definição de capital social a participação cidadã, cultura política, convivência e cultura cívica.

Putnam (apud SANTOS et al, 2009) incorpora todos esses pontos e defende que capital social são práticas sociais, normas e relações de confiança que existem entre cidadãos em uma dada sociedade, da mesma forma como sistemas de participação e associação que estimulam a cooperação. Desta maneira, quanto maior e mais rico for o número de possibilidades associativas de uma sociedade, maior será o volume de capital social. Para ele, as tradições cívicas nos permitem projetar o grau de desenvolvimento que uma sociedade terá de maneira mais evidente do que a dimensão econômica, sendo, por essa lógica, os aspectos econômicos subordinados aos aspectos políticos. Assim, o desempenho institucional estará diretamente condicionado ao meio.

Conforme Santos et al (2009), o ponto central para Putnam é que a confiança, a colaboração e os espaços de participação social entre o Estado e a sociedade são fatores positivos e essenciais para o desempenho das instituições políticas

O objetivo deste tópico é demonstrar a ação combinada, de baixo para cima, do capital social sobre as instituições do Estado (sobre os serviços públicos prestados por este), assim como os efeitos das dotações orçamentárias, de cima para baixo, também sobre os serviços públicos prestados à comunidade.

Em um primeiro momento, a partir de pesquisa tipo survey (NUPESAL/UFRGS em 2005, banco de dados), será analisado o nível de confiança interpessoal em ambas as cidades. Isso inclui suas dotações de capital social a partir de uma das variáveis-chave, nível de confiança interpessoal, a satisfação das populações locais com os serviços de educação, saúde e segurança, bem como o cruzamento das variáveis níveis de confiança nas associações comunitárias e avaliação dos serviços públicos. Em um segundo momento, analisaremos os valores de dotação orçamentária de cada área pesquisada e, posteriormente, sua relação com a satisfação das populações.

\section{Capital Social e Serviços Públicos}

Analisando-se na perspectiva do capital social, portanto, de baixo para cima, o Gráfico 1, que trata do nível de confiança interpessoal, mostra que mais da metade $(50,2 \%)$ dos entrevistados em Montevidéu acredita que se pode confiar nas pessoas. Por outro lado, em Porto Alegre, menos de 1/3 
$(32,9 \%)$ responderam da mesma forma. Esses dados indicam que, no nível de confiança interpessoal, os montevideanos demonstram um comportamento de sinal positivo e que é significativamente maior do que a confiança revelada pelos porto-alegrenses, com índice 17,3\% superior. Portanto, em Montevidéu as pessoas confiam mais umas nas outras do que em Porto Alegre.

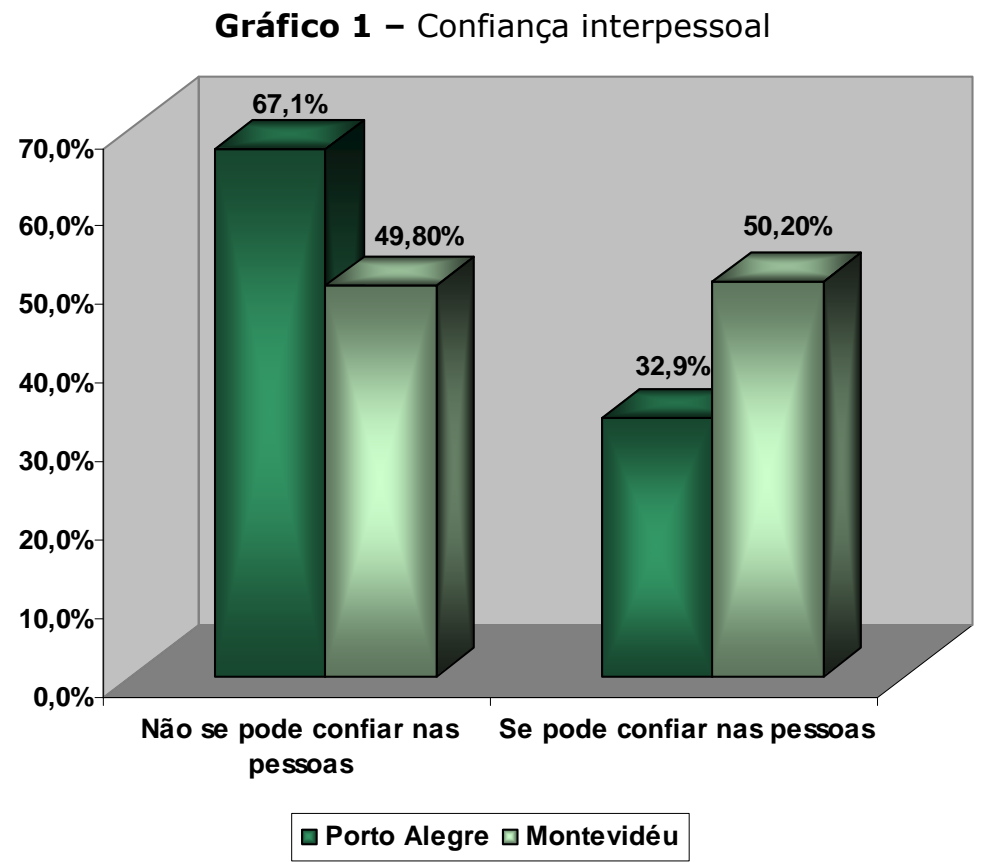

Fonte: adaptado de NUPESAL/UFRGS (2005).

Sendo o elemento confiança considerado de peso essencial na composição do capital social, não é demasiado reprisar o fato de que o nível de capital social em Montevidéu, excedendo de maneira significativa o apresentado em Porto Alegre, permite a percepção de maior consistência no tecido social. Baquero (2007), elaborando um índice de capital social comparado dessas cidades e, portanto, reunindo um conjunto de perguntas indicativas, demonstra que Montevidéu tem um índice alto de $7,6 \%$, contra $0,0 \%$ de Porto Alegre.

Também segundo a corrente teórica por este trabalho adotada, sociedades com índices maiores de confiança interpessoal tendem a avaliar mais positivamente as instituições, como veremos a seguir.

\section{Satisfação com os Serviços Públicos}

O Gráfico 2 trabalha com os dados sobre a avaliação da qualidade dos serviços públicos de educação oferecidos às populações nas duas cidades em 
estudo. Novamente, as avaliações sobre esta prestação institucional se mostram superiores em Montevidéu, comparativamente a Porto Alegre.

Gráfico 2 - Educação

Como avalias a qualidade dos serviços de sua cidade no quesito: Educação

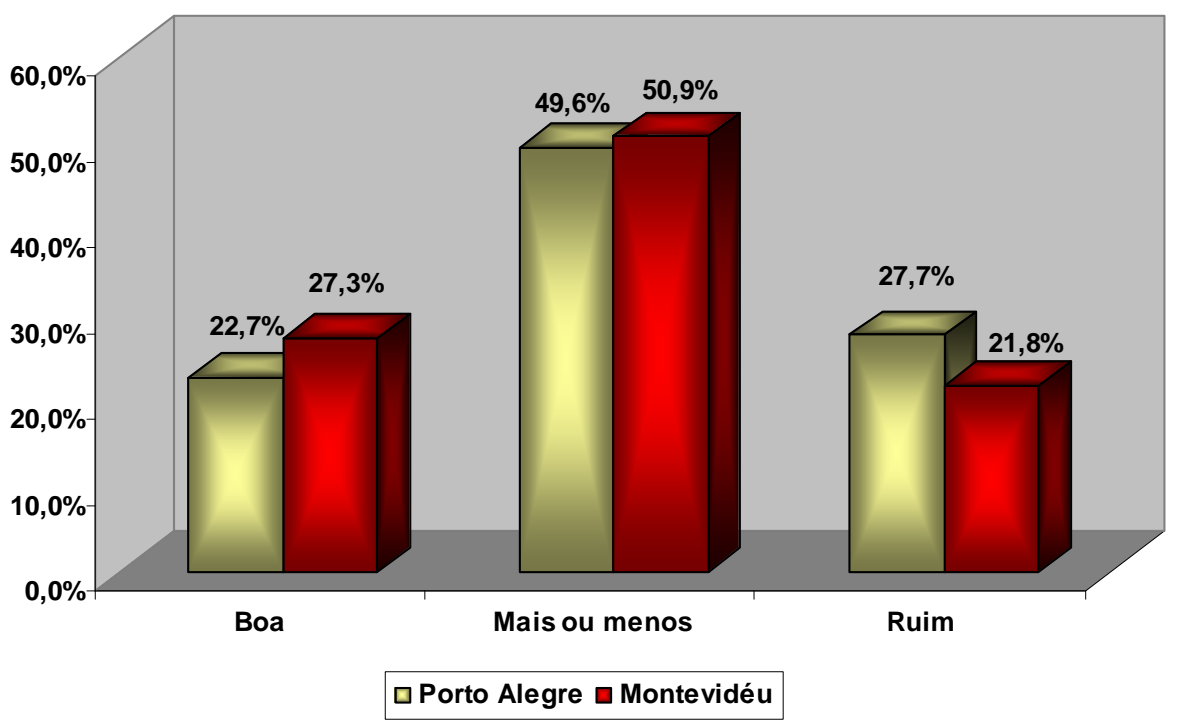

Fonte: adaptado de NUPESAL/UFRGS (2005).

Para $27,3 \%$ dos montevideanos, a educação recebeu avaliação boa, ao passo que, em Porto Alegre, $22,7 \%$ dos entrevistados optaram por essa notação. Vale referir que os percentuais somados para formar a tendência positiva confirmam o maior apoio ao desempenho do governo em Montevidéu em um índice que, somando a avaliação mais ou menos $(50,9 \%)$ com a boa $(27,3 \%)$, atinge $78,2 \%$. Em Porto Alegre, a soma da opinião mais ou menos $(49,6 \%)$ com a boa $(22,7 \%)$ chega a $72,3 \%$ na tendência positiva que, novamente no lado brasileiro, é inferior à tendência negativa, chegando a $77,3 \%$ considerando a avaliação mais ou menos $(49,6 \%)$ e a ruim $(27,7 \%)$. Em Montevidéu, a percepção de tendência negativa da avaliação da educação é de $72,7 \%$, na soma de mais ou menos $(50,9 \%)$ com ruim $(21,8 \%)$.

A insatisfação do porto-alegrense, medida em $27,7 \%$ em relação à educação, é corroborada por um dado: a posição do município no Índice de Desenvolvimento da Educação Básica (IDEB), hoje, é a décima quarta no 
país, atrás de capitais do Nordeste e de estados pequenos, conforme nos informou a secretária municipal de Educação de Porto Alegre, Cleci Jurah ${ }^{3}$.

Quando observamos a avaliação que a população entrevistada faz do quesito saúde, percebemos que mais da metade $(52,2 \%)$ dos portoalegrenses qualifica como ruim esse serviço. Já em Montevidéu, menos de 1/3 $(31,5 \%)$ dos entrevistados têm opinião ruim a respeito do serviço de saúde prestado pelo Estado.

\section{Gráfico 3 - Saúde}

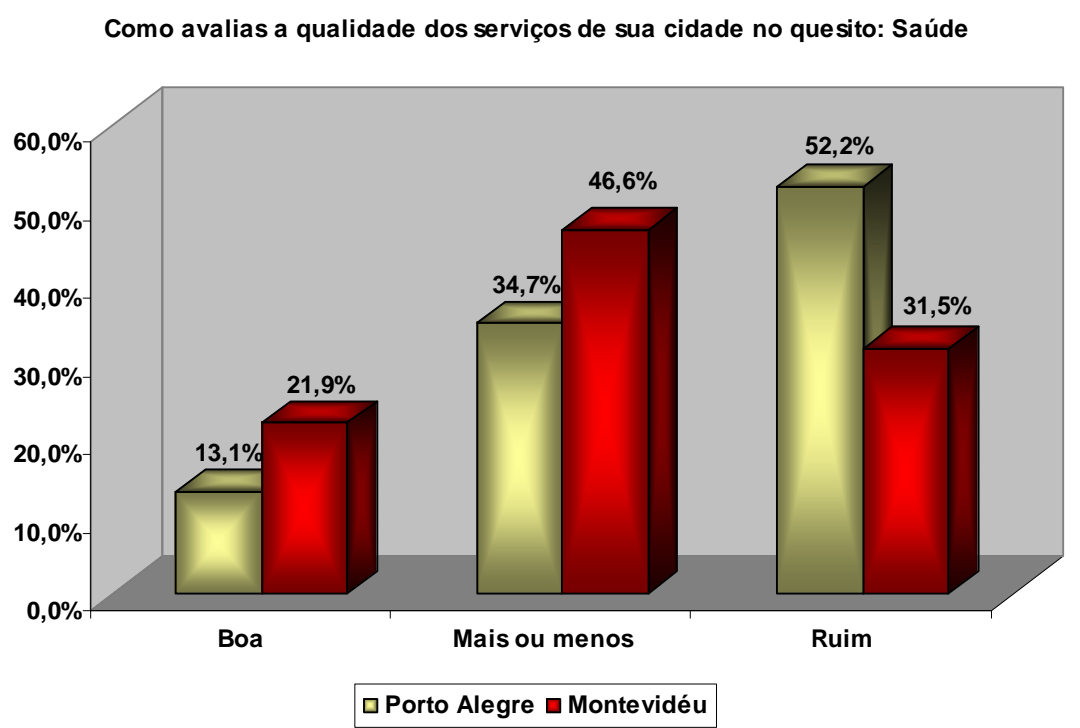

Fonte: adaptado de NUPESAL/UFRGS (2005).

Em sentido inverso, dos que consideram boa a prestação de serviço de saúde, a proporção positiva em Montevidéu é ainda maior do que em Porto Alegre, em um índice de $21,9 \%$ contra $13,1 \%$, respectivamente. Se somarmos a avaliação mais ou menos $(46,6 \%)$ com a boa $(21,9 \%)$, a satisfação com os serviços de saúde, em Montevidéu, chega a $68,5 \%$, ou seja, mais de $2 / 3$ dos montevideanos avaliam a saúde tendendo à positividade. Em Porto Alegre, esta soma de tendência positiva não atinge a marca de $50 \%$, e a avaliação de tendência negativa, mais ou menos $(34,7 \%)$ somada à ruim $(52,2 \%)$, atinge o índice de $86,9 \%$ dos que reprovam o desempenho institucional. Em Montevidéu, $78,1 \%$ da população manifestam a tendência de avaliação negativa.

\footnotetext{
${ }^{3}$ Entrevista concedida a Sonia Santos em Porto Alegre, 29 de abril de 2009. 
Mesmo que a universalização dos atendimentos e serviços de saúde tenha chegado com 20 anos de defasagem em comparação ao Brasil - uma vez que apenas em 2008 é que o Uruguai, na sua Reforma de la Salud, introduz esse dispositivo -, a avaliação positiva, na visão do Diretor Financeiro da Intendência de Montevidéu, Enrique Cabrera ${ }^{4}$, é uma resposta ao atendimento de saúde pública oferecido à população através de uma rede de policlínicas bem equipadas instrumentalmente e com quadro qualificado de médicos, que possui qualidade superior ao serviço oferecido em Porto Alegre.

Outro indicador de saúde muito importante e objetivo é o da expectativa de vida, que tem aumentado gradativamente na cidade de Porto Alegre e no estado do Rio Grande do Sul. Os dados estatísticos são medidos pelo Instituto Brasileiro de Geografia e Estatística (IBGE) e pela Secretaria de Saúde. Segundo dados do IBGE (2007), a expectativa de vida dos gaúchos é de 75 anos.

O Gráfico 4 apresenta a avaliação da população quanto ao quesito segurança pública. Ambas as cidades apresentaram a tendência de avaliar negativamente esse aspecto, sendo que, em Montevidéu, menos da metade $49,7 \%$ - julgam a segurança pública como ruim, enquanto mais de $2 / 3$ $(68,3 \%)$ dos porto-alegrenses assim avaliam este ponto, com uma diferença de $18,6 \%$. Pode-se dizer que, em Porto Alegre, a sensação de insegurança é $30 \%$ maior do que em Montevidéu, e que a insatisfação é maior em Porto Alegre.

Gráfico 4 - Segurança pública

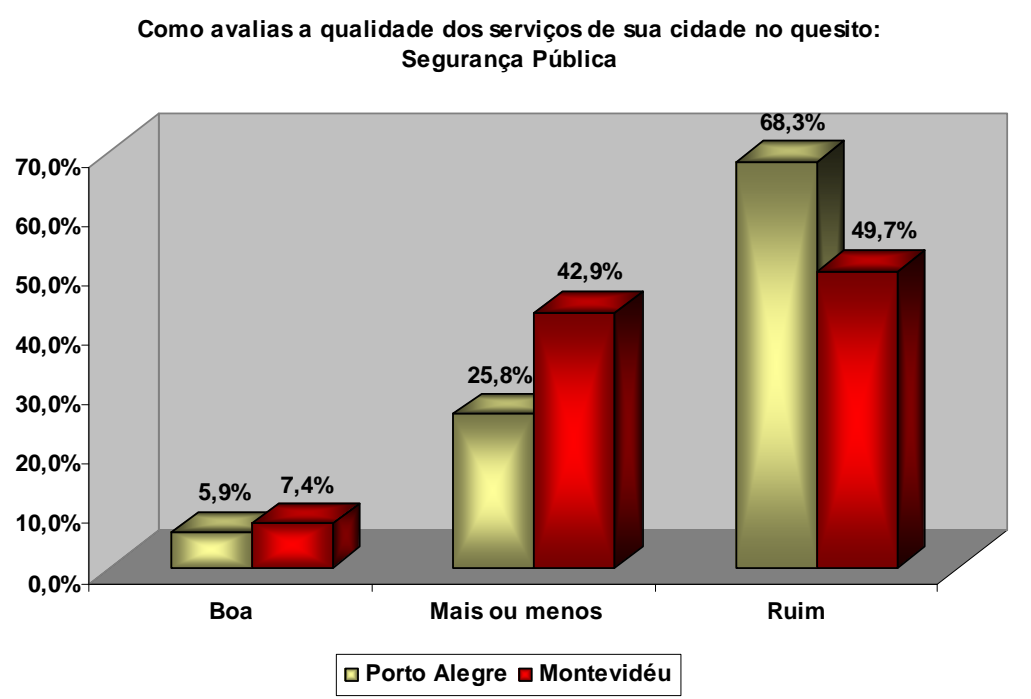

Fonte: adaptado de NUPESAL/UFRGS (2005).

\footnotetext{
${ }^{4}$ Entrevista concedida a Sonia Santos em Montevidéu, 11 fevereiro de 2008.
}

REVISTA DEBATES, Porto Alegre, v.5, n.1, p. 25-45, jan.-jun. 2011. 
Vimos que, cotejando um indicador de capital social, o índice de capital social e a avaliação dos serviços públicos prestados, há uma tendência de os uruguaios terem índice de capital social maior do que Porto Alegre e, consequentemente, um maior índice de satisfação com os serviços prestados.

Vejamos agora o cruzamento dos dados para verificar o grau de associação entre as variáveis capital social e satisfação com os serviços públicos.

\section{Cruzando variáveis}

Do cruzamento dos dados, com o auxílio do programa SPSS, sobre a relação da avaliação de desempenho boa nas diferentes áreas com a confiança nas associações comunitárias (como indicador de capital social), em Porto Alegre e em Montevidéu, obtém-se indicações que confirmam nossa tese de que quanto maior o índice de confiança societal, interpessoal, em vizinhos e em associações, maior será a satisfação manifestada pelas pessoas em relação às instituições ${ }^{5}$.

Tabela 1 - Avaliação dos Serviços Públicos e Confiança nas Associações -

\begin{tabular}{ccc} 
& \multicolumn{3}{c}{ Porto Alegre $(\%)^{6}$ PORTO ALEGRE } \\
\hline Avaliação de & \multicolumn{2}{c}{ Confiança nas associações } \\
comunitárias \\
Desempenho por Área & \multicolumn{2}{c}{ Nono confia } \\
\cline { 2 - 3 } (Avaliação Boa) & $37,9^{*}$ & 15,5 \\
Saúde & $38,2 *$ & 13,7 \\
Educação & 40,7 & 18,5 \\
Segurança & Confia muito &
\end{tabular}

Fonte: Pesquisa Capital Social e Desenvolvimento Sustentável na Construção da Cidadania e Melhoria da Qualidade de Vida: estudo comparado entre cidades do Brasil, Uruguai e Chile NUPESAL/UFRGS/CNPQ - 2005.

*Porto Alegre $\mathrm{N}=510 / \chi^{2}=10.638 \mathrm{P}<0,05$

$* *$ Porto Alegre $\mathrm{N}=510 / \chi^{2}=21.460 \mathrm{P}<0,05$

Conforme a Tabela 1, relativa a Porto Alegre, pode-se perceber que, das pessoas entrevistadas que dizem confiar muito nas associações comunitárias, 37,9\% avaliam a saúde como boa; entre os que responderam

\footnotetext{
${ }^{5}$ A questão era: "Em relação às instituições que eu vou ler, gostaria de saber se o/a sr./a. confia muito, pouco ou não confia no(a): Congresso Nacional (deputados federais/senadores), Governo Federal (presidente/ministros), Assembleia Legislativa, Governo Estadual, Câmara Municipal, Governo Municipal, Judiciário, Partidos Políticos, Polícia, Igreja, Família, Vizinhos, Associações Comunitárias, Sindicatos, Meios de Comunicação)". Escolhemos esta variável, Associações Comunitárias, por ter mostrado um maior grau de associação entre a confiança interpessoal $X$ políticas públicas. Em estudos posteriores, pode-se incluir as demais, porém, dados os objetivos deste trabalho e seus limites de investigação e tempo, optamos por trabalhar somente com esta.

${ }^{6} \mathrm{O}$ índice não soma $100 \%$ porque somente a avaliação boa está sendo considerada.
} 
que não confiam nas associações comunitárias, o número caiu para 15,5\%. Essa é a mesma tendência dos que responderam que confiam muito nas associações comunitárias $(38,2 \%)$ e das pessoas que consideram boa a prestação dos serviços na área da educação. Por outro lado, dos que dizem não confiar nessa instituição, o número despenca para 13,7\%. Por fim, dentre os entrevistados de Porto Alegre, das pessoas que confiam muito nas associações comunitárias, $40,7 \%$ avaliam como boa a prestação de serviços de segurança, ao passo que, dentre os que dizem não confiar nas referidas associações, o número diminui para $18,5 \%$. Ou seja, a avaliação positiva cai proporcionalmente à confiança.

Muito embora os números comprovem esta tendência, aplicamos o teste estatístico do qui-quadrado com o objetivo de avaliar se havia associação entre as variáveis confiança nas associações comunitárias e avaliação satisfatória dos serviços.

Dos três quesitos analisados - saúde, educação e segurança -, comprovamos que apenas a segurança não encontrou significância estatística, sendo que os restantes mostraram forte associação.

Tabela 2 - Avaliação dos Serviços Públicos e Confiança nas Associações - Montevidéu (\%)

\begin{tabular}{|c|c|c|}
\hline \multicolumn{3}{|c|}{ Montevidéu } \\
\hline \multirow{2}{*}{$\begin{array}{c}\text { Avaliação de } \\
\text { Desempenho por Área } \\
\text { (Avaliação Boa) }\end{array}$} & \multicolumn{2}{|c|}{$\begin{array}{c}\text { Confiança nas associações } \\
\text { comunitárias }\end{array}$} \\
\hline & Confia muito & Não confia \\
\hline Saúde & 53,4 & 9,7 \\
\hline Educação & 53,0 & 7,5 \\
\hline Segurança & $45,9 *$ & 8,1 \\
\hline
\end{tabular}

Fonte: Pesquisa Capital Social e Desenvolvimento Sustentável na Construção da Cidadania e Melhoria da Qualidade de Vida: estudo comparado entre cidades do Brasil, Uruguai e Chile NUPESAL/UFRGS/CNPQ - 2005.

*Montevidéu $\mathrm{N}=500 / \chi^{2}=24.462 \mathrm{P}<0,05$

Em Montevidéu, como podemos observar na Tabela 2, seguimos a mesma constatação da tabela de Porto Alegre. Verifica-se, no cruzamento de dados entre confiança nas associações comunitárias e avaliação boa nas áreas, uma tendência de as pessoas que confiam mais indicar avaliação boa do desempenho das instituições e, portanto, dos serviços públicos prestados. Dos que confiam nas associações comunitárias, 53,4\% avaliaram como boa a saúde; entre os que não confiam, a avaliação foi de $9,7 \%$. Se observarmos a educação, daqueles que confiam muito, 53\% avaliaram essa variável como boa. Já entre os que não confiam, esse percentual caiu para $7,5 \%$.

Na segurança, dos que confiam nas associações comunitárias, 45,9\% a avaliam como boa, e entre os que não confiam o percentual é bem menor $(8,1 \%)$. 
Os cruzamentos realizados comprovam que quanto maior o nível de confiança nas associações comunitárias, mais positivamente as pessoas avaliam os serviços prestados pelas instituições governamentais, tanto em Montevidéu como em Porto Alegre. Aplicando-se também o teste estatístico do qui-quadrado com o objetivo de avaliar se havia associação entre as variáveis confiança nas associações comunitárias e avaliação satisfatória dos serviços, constatamos que, neste caso, somente segurança apresentou significância.

$\mathrm{Na}$ sequência, analisaremos, de cima para baixo, o impacto das dotações orçamentárias na avaliação dos serviços governamentais pelas populações de Porto Alegre e Montevidéu.

\section{Orçamentos e Satisfação com os Serviços Públicos}

Passamos agora à checagem do valor de investimentos feitos em cada uma das áreas analisadas nas duas cidades em tela. Por ter sido realizada a fotografia social no primeiro semestre do ano de 2005, optou-se por trabalhar com os balancetes do ano anterior, 2004, por entender-se que seriam eles que estariam refletidos nas respostas dadas aos questionamentos do survey.

Antes, porém, de passarmos à análise propriamente dita, é importante referir que, entre as cidades de Porto Alegre e Montevidéu, há significativa distinção de competências estabelecidas e de destinações orçamentárias fixadas para os recursos das instituições apreciadas por este trabalho.

Há que se apontar que é constitucionalmente imputado aos municípios brasileiros um percentual mínimo de investimentos que deverá ser obedecido nas áreas de educação e de saúde, a saber, o artigo 212 da Constituição Federal (BRASIL, 1988), segundo o qual "vinte e cinco por cento, no mínimo, da receita resultante de impostos, compreendida a proveniente de transferências" deve ser destinada à "manutenção e desenvolvimento do ensino".

Na saúde, de acordo com a Emenda Constitucional n. 29, de 13 de setembro de 2000 (BRASIL, 2000), os municípios devem aplicar pelo menos $15 \%$ do produto da arrecadação dos impostos, como forma de garantir os serviços desta área.

Já no universo platino, a educação não compete à Intendência Municipal, mas ao governo nacional, salvo a administração das creches, que recebem o aporte de recursos por parte da Intendência. Também na saúde a competência é do governo nacional, ressalvando a atuação das policlínicas, nas quais há destinação de recursos orçamentários da Intendência. Cabe ressaltar que a gestão da política pública, tanto de educação quanto de saúde, é feita no âmbito nacional, cabendo à Intendência tão somente a gestão orientada. A gestão da segurança pública compete igualmente ao governo central e é realizada pelo Ministério do Interior, de acordo com a Constituição.

Neste sentido, para podermos comparar as duas cidades em tela, recortamos do total dos investimentos da área de educação, saúde e 
segurança do Estado uruguaio, somente os valores destinados à intendência municipal de Montevidéu. No caso de Porto Alegre, temos o orçamento público municipal conforme tabelas abaixo ${ }^{7}$.

Com relação ao quesito segurança pública, deve-se expor que, no Brasil, as atribuições constitucionais dividem as competências entre os entes federais e estaduais, restando aos municípios as questões de trânsito e a guarda dos seus próprios públicos.

A Tabela 3 a seguir mostra os volumes de investimentos, em moeda brasileira, em Porto Alegre e em Montevidéu ${ }^{8}$, em cada uma das áreas investigadas, tendo por base os orçamentos publicados pelos respectivos governos no ano de $2004^{9}$.

Tabela 3 - Gastos Comparados nos Serviços Públicos por Área (R\$) - 2004

\begin{tabular}{ccc}
\hline & Porto Alegre & Montevidéu \\
\hline Educação e Cultura & $262.470 .679,00$ & $530.076 .106,07$ \\
Saúde & $478.927 .276,60$ & $147.259 .499,06$ \\
Segurança & $12.565 .694,68$ & $119.310 .086,97$ \\
\hline Total dos gastos & $895.050 .763,10$ & $817.925 .460,15$ \\
\hline Número de habitantes & 1.360 .590 & 1.325 .853 \\
Fonte: Tribunal de Contas do Estado do Rio Grande do Sul (2009); Intendência Municipal de \\
\multicolumn{3}{c}{ Montevidéu (2004). }
\end{tabular}

Desdobrando os valores investidos em cada área, descritos acima, pelo número total de habitantes, a tabela a seguir mostra a relação do valor gasto por cada indivíduo de Porto Alegre e de Montevidéu.

\footnotetext{
7 Então a comparação é entre o orçamento público municipal de Porto Alegre e o percentual do orçamento público federal destinado à intendência de Montevidéu.

8 Nos números de Montevidéu, o item marcado com asterisco é resultante de equação que considera o total do orçamento nacional da área, dividido pela população do país e multiplicado pelo número da população da cidade indicado na última linha da tabela.

9 Em Montevidéu, na área de saúde, o valor indicado é o total orçamentário destinado pela Intendência Municipal à rede de policlínicas, visto que os outros serviços são mantidos pelo orçamento nacional. Já na segurança, diferenciando-se do que ocorre em Porto Alegre, a Intendência Municipal de Montevidéu investe um valor próprio significativo.

10 Conforme o Banco Central do Brasil, em dezembro de 20041 Real (R\$), equivalia 9,82 Pesos Uruguaios. Assim, a fim de convertermos os Pesos em Reais, dividimos o valor dos orçamentos pela equivalência dos Pesos Uruguaios. Disponível em <http://www4.bcb.gov.br/pec/conversao/conversao.asp>. Acesso em: 20 fev. 2010.
}

REVISTA DEBATES, Porto Alegre, v.5, n.1, p. 25-45, jan.-jun. 2011. 
Tabela 4 - Gastos Comparados por Habitante nos Serviços Públicos (R\$) Montevidéu e Porto Alegre - 2004

\begin{tabular}{ccc}
\hline & Porto Alegre & Montevidéu \\
\hline Educação e Cultura & 192,91 & 399,80 \\
Saúde & 352,00 & 111,07 \\
Segurança & 9,24 & 89,99 \\
\hline Número de Habitantes & 1.360 .590 & 1.325 .853 \\
\hline Fonte: Tribunal de Contas do Estado do Rio Grande do Sul (2009); Intendência Municipal de \\
\end{tabular}

Como podemos observar em uma primeira leitura, Porto Alegre investiu mais quando comparada com os investimentos que recebeu a cidade uruguaia na área da saúde, com $R \$ 352,00$ contra $R \$ 111,07$, uma diferença de $R \$ 240,93$ a mais do que Montevidéu.

Montevidéu, na comparação com os investimentos de Porto Alegre, teve maiores números em educação e cultura, com R\$399,80 contra R\$ 192,91 , uma diferença de $\mathrm{R} \$ 206,89$ a mais. Na área de segurança, os uruguaios também tiveram mais investimentos, $R \$ 89,99$ contra $R \$ 9,24$. Nesta área, Montevidéu investiu por pessoa $\mathrm{R} \$ 80,75$ a mais do que Porto Alegre.

As tabelas seguintes relacionam o grau de satisfação, avaliação boa, com o valor gasto por indivíduo nas três áreas, em cada uma das duas cidades, a começar por Porto Alegre.

Tabela 5 - Gastos por Habitante e Satisfação com Serviços Públicos Porto Alegre - 2004

\begin{tabular}{ccc}
\hline & Avaliação Boa (\%) & Porto Alegre (R\$) \\
\hline Educação e Cultura & 22,7 & 192,91 \\
Saúde & 13,1 & 352,00 \\
Segurança & 5,9 & 9,24 \\
\hline Número de Habitantes & 1.360 .590 & 1.325 .853 \\
\hline Fonte: Tribunal de Contas do Estado do Rio Grande do Sul (2009) e Pesquisa Capital Social e \\
Desenvolvimento Sustentável na Construção da Cidadania e Melhoria da Qualidade de Vida: \\
estudo comparado entre cidades do Brasil, Uruguai e Chile - NUPESAL/UFRGS/CNPQ - 2005.
\end{tabular}

De forma geral, olhando-se para os dados de Porto Alegre, constatamos, em uma primeira observação, que a avaliação positiva varia quase que de acordo com os investimentos orçamentários. Foram investidos $\mathrm{R} \$ 9,24$ em segurança por habitante na cidade de Porto Alegre e a satisfação ficou em 5,9\%; na saúde, investiu-se $R \$ 352,00$ por habitante e a satisfação subiu, então, para 13,1\%. Na educação e cultura, investiu-se R\$192,91 (apesar de ser menos que a saúde) e a satisfação subiu para 22,7\%. A área da saúde em Porto Alegre certamente apresenta maiores problemas do que a área da educação, mostrando que, apesar dos recursos orçamentários destinados, eles não são suficientes para aplacar os problemas dessa área. 
Observando-se os dados relativos a Montevidéu, constatamos, de forma muito mais linear do que Porto Alegre, que a satisfação do uruguaio varia de acordo com os investimentos orçamentários: quanto mais investimento, mais satisfação (Tabela 6). Dos $R \$ 89,99$ investidos em segurança, a satisfação ficou em $7,4 \%$, aumentando para $21,9 \%$ quando o orçamento da saúde também aumentou para $R \$ 111,07$, e subindo mais ainda para $27,3 \%$ quando o orçamento chega a $\mathrm{R} \$ 399,80$ por habitante em educação e cultura.

Tabela 6 - Gastos por Habitante e Satisfação com Serviços Públicos Montevidéu - 2004

\begin{tabular}{ccc}
\hline & Avaliação Boa (\%) & Montevidéu (R\$) \\
\hline Educação e Cultura & 27,3 & 399,80 \\
Saúde & 21,9 & 111,07 \\
Segurança & 7,4 & 89,99 \\
\hline Número de Habitantes & 1.360 .590 & 1.325 .853
\end{tabular}

Fonte: Intendência Municipal de Montevidéu (2004) e Pesquisa Capital Social e Desenvolvimento Sustentável na Construção da Cidadania e Melhoria da Qualidade de Vida: estudo comparado entre cidades do Brasil, Uruguai e Chile - NUPESAL/UFRGS/CNPQ - 2005.

A satisfação média em Montevidéu nas três áreas ficou em $56,6 \%$, com um gasto médio nas três áreas de $\mathrm{R} \$ 200,2$ por habitante. Em Porto Alegre, a satisfação caiu para $41,7 \%$, e o orçamento médio das três áreas ficou um pouco abaixo, em R\$184,7 por habitante.

Claramente há uma relação entre gastos e satisfação, porém nos parece que esta variação orçamentária de $R \$ 15,5$ gastos a mais em Montevidéu não seria suficiente para explicar os cerca de 10 pontos percentuais de satisfação a mais que os uruguaios de Montevidéu têm sobre os porto-alegrenses ${ }^{11}$.

A apresentação dos dados referentes a essas dotações orçamentárias teve o propósito de demonstrar, neste trabalho, a relação existente entre satisfação com serviços públicos e investimentos em uma primeira aproximação. Entretanto, algumas ressalvas precisam ser feitas. Como não tivemos comparações longitudinais que pudessem aferir ano a ano o investimento e a satisfação das populações pesquisadas (pelos limites desta pesquisa), nossos dados não são definitivos, justamente pelo fato de que o valor orçamentário investido pode não ser o suficiente para aquela realidade, fazendo com que um orçamento maior em Porto Alegre, como vimos, não altere significativamente a satisfação daquela população, pois o problema é muito mais grave do que em Montevidéu, por exemplo. Daí a importância novamente das análises longitudinais para se estudar alterações sob o

11 A cada 15 Reais teríamos o equivalente a 10 pontos percentuais de diferença na satisfação? Este é um ponto importante que estudos longitudinais poderiam responder.

REVISTA DEBATES, Porto Alegre, v.5, n.1, p. 25-45, jan.-jun. 2011. 
impacto de determinadas políticas. Então, essa linearidade entre investimento e satisfação deve ser relativizada.

Por outro lado, procuramos demonstrar que o capital social impacta positivamente sobre a satisfação dos serviços públicos nas diferentes cidades. Quanto maior é a "confiança horizontal" dos cidadãos para além da família, maiores são as chances desses serviços de serem melhor avaliados, ou, em outras palavras, que esses serviços funcionem adequadamente para o cidadão.

Essa combinação entre a cultura política de uma determinada região ou localidade (capital social) e suas iniciativas institucionais (dotações orçamentárias) pode facilitar a implementação de políticas públicas pelos gestores. Procuramos, aqui, dimensionar seus impactos, aludindo para o sinergismo possível entre ambas as variáveis, uma de curto prazo, como as dotações orçamentárias, e outra de médio e longo prazo, como o capital social.

\section{Considerações finais}

Como apontamentos finais, podemos ainda sublinhar que o nível de confiança interpessoal medido identifica, em Montevidéu, números maiores do que os verificados em Porto Alegre, refletindo índice maior de consistência no tecido social da capital platina.

A maioria dos gráficos apresentados mostra que os números que mediram o grau de satisfação da comunidade de Montevidéu com as suas instituições reforçam a confiança da sociedade em relação ao poder público, em uma comparação com a avaliação dos resultados obtidos na população de Porto Alegre, que se revela menos satisfeita com os serviços públicos. Nos resultados encontrados a partir da aplicação dos testes de qui-quadrado no SPSS, constata-se que, de fato, a confiança interpessoal tem relação com a avaliação positiva dos serviços públicos e que o capital social impacta positivamente sobre as instituições públicas nas cidades.

Quando se relacionam os números da avaliação boa com os valores de investimentos orçamentários destinados aos serviços pesquisados nas duas cidades, os dados de Porto Alegre sobre saúde e educação revelam que o volume de verbas aplicado não produz o grau de satisfação proporcional que se verifica em Montevidéu: $27,3 \%$ e $21,5 \%$ na capital uruguaia contra $22,7 \%$ e $13,1 \%$ em Porto Alegre. Isso pode ser explicado, em parte, pelo menor índice de capital social que se encontra na sociedade porto-alegrense, mais negativa na percepção dos serviços públicos.

$\mathrm{Na}$ educação, Montevidéu recebe bem mais investimentos do que Porto Alegre e, em correspondência, obtém satisfação também superior no quesito, mas em sáude investe-se menos e tem-se maior satisfação do que em Porto Alegre.

Importante enfatizar que, apesar da garantia constitucional de investimentos orçamentários destinados às áreas de saúde e educação, no 
caso brasileiro isso não se reflete no grau de satisfação da população com esses quesitos, o que podemos atribuir ao baixo índice de capital social que a sociedade porto-alegrense apresenta e que interfere negativamente na sua participação e no fortalecimento do seu tecido social, tendo como consequência uma menor cobrança junto ao poder público por uma prestação de serviços de melhor qualidade.

Com base nesta investigação comparada, os dados sugerem algumas ações que podem vir a se constituir em políticas públicas adotadas em Porto Alegre e em Montevidéu, visando o desenvolvimento das localidades e, consequentemente, a inclusão social de setores expressivos dessas populações.

Por fim, este trabalho representa também um indicador para que os gestores invistam na qualidade das suas sociedades e em políticas públicas, por exemplo, que incentivem o dinamismo e a ativação da sociedade, quer seja na construção de parques, praças, áreas esportivas ou mesmo na diminuição da criminalidade nessas regiões. Essas medidas podem favorecer a interação interpessoal e, portanto, facilitar a própria ação do Estado. As dotações orçamentárias dos governos locais podem e devem ser combinadas com esta ativação da sociedade para, juntas e sinergeticamente, produzirem serviços públicos de melhor qualidade e, consequentemente, possibilitarem a inclusão de parcelas significativas das populações locais que se encontram historicamente marginalizadas dos benefícios produzidos pelo Estado.

É importante ressaltar ainda que este estudo, muito embora limitado aos itens demonstrados nos gráficos expostos, não teve a pretensão de açambarcar a totalidade da complexidade das relações entre Estado e sociedade nas duas cidades estudadas, mas tão somente propor uma perspectiva de análise que chamasse a atenção para o importante papel protagonista que pode exercer a sociedade latina em parceria com o Estado.

Sonia Santos é Mestre em inclusão Social e Acessibilidade pela Universidade Feevale.

Email: ss.soniasantos@gmail.com

Everton Santos é Doutor em Ciência Política pela UFRGS, atualmente é Professor Titular na Universidade Feevale, líder do Grupo de Pesquisa em Desenvolvimento Regional e Coordenador do Mestrado em Inclusão Social e Acessibilidade. É Professor Adjunto na Universidade Luterana do Brasil (Ulbra) no ensino de Graduação e Pós-Graduação.

Email: evertons@feevale.br

Cristina Ennes é Doutora em História Ibero-Americana pela PUC/RS, Professora Adjunta na Universidade Feevale no Mestrado em Processos Culturais e Diretora do Instituto de Ciências Humanas Letras e Artes (ICHLA)

Email: crisennes@feevale.br 
Valdir Pedde é Doutor em Antropologia pela UFRGS, atualmente é Professor Titular na Universidade Feevale no Mestrado em Inclusão Social e Acessibilidade e pesquisador no Grupo Estudos em Desenvolvimento Regional. Email: valpe@feevale.br

\section{Referências:}

ALMOND, Gabriel; VERBA, Sidney. The Civic Culture: political attitudes and democracy in five nations. Princeton: Princeton University Press, 1989.

BAQUERO, Marcello. Democracia e Desigualdades na América Latina: novas perspectivas. Porto Alegre: UFRGS, 2007.

BRASIL. Constituição Federal de 1988. Disponível em: <http://www.planalto.gov.br/ccivil_03/Constituicao/Constituiçao.htm>. Acesso em: 20 fev. 2010.

. Emenda Constitucional n. 29, de 13 de setembro de 2000. Altera os artigos 34, 35, 156, 160, 167 e 198 da Constituição Federal e acrescenta artigo ao Ato das Disposições Constitucionais Transitórias, para assegurar os recursos mínimos para o financiamento das ações e serviços públicos de saúde.

<http://www.planalto.gov.br/ccivil_03/Constituicao/Emendas/Emc/emc29.ht m>. Acesso em: 10 jan. 2008.

CEPAL. Comissión Económica para América Latina y El Caribe. 2008. Disponível em: <http://www.eclac.org/>. Acesso em: 09 jan. 2009.

FUKUYAMA, Francis. Confiança: as virtudes sociais e a criação da prosperidade. Rio de Janeiro: Rocco, 1996.

HALL, Peter A.; TAYLOR, Rosemary C. R. As Três Versões do NeoInstitucionalismo. Lua Nova, São Paulo, n. 58, p. 193-224, 2003.

HALL, Stuart. A Identidade cultural na Pós-modernidade. 11. ed. Rio de Janeiro: DP\&A, 2006.

INSTITUTO BRASILEIRO DE GEOGRAFIA E ESTATÍSTICA. Tábuas completas de mortalidade, 2007.2 Disponível em: <http://www.ibge.gov.br/home/presidencia/noticias/noticia_impressao.php?id _noticia $=1275>$. Acesso em: 20 fev. 2010.

INTENDÊNCIA MUNICIPAL DE MONTEVIDÉU. Orçamento municipal. Mímeo. 2004. 
NORTH, Douglas. Institutions, Institutional Change and Economic Performance. New York: Cambridge University Press, 2007.

PRZEWORSKI, Adam. A última instância. As instituições são a causa primordial do desenvolvimento econômico? Novos Estudos CEBRAP, São Paulo, n. 72, p. 59-77, jul. 2005.

PUTNAM, Robert. Comunidade e Democracia: a experiência da Itália moderna. Rio de Janeiro: FGV, 2005.

RANINCHESKI, Sonia. Capital social e cultura política em tempos de crise econômica: os casos de Brasil e Uruguai. In: BAQUERO, Marcello (Org.). Capital Social, Desenvolvimento Sustentável e Democracia na América Latina. Porto Alegre: UFRGS, 2007. p. 169-194.

SANTOS, Everton Rodrigo; BITARELLO, Jucelaine; MONTARDO, Sandra; PEDDE, Valdir. Contrastes regionais que fazem a diferença no Rio Grande do Sul: capital social e desempenho institucional. Revista Brasileira de Gestão e Desenvolvimento Regional, Taubaté, v. 6, n. 2, p. 157-187, mai.-ago. 2010.

SANTOS, Everton Rodrigo; BITARELLO, Jucelaine; SANTOS, Sônia; PEDDE, Valdir. Os desafios da democratização do Estado: instituições e cultura política. Revista do ICSA - Gestão e Desenvolvimento, Novo Hamburgo, v. 6, n. 1, p. 137-144, jan. 2009.

SANTOS, Everton Rodrigo; FERREIRA, Gustavo Assed. Capital social e desempenho institucional na América Latina: um desenho teórico preliminar. Caesura, Canoas, v. 31, p. 15-28, jul.-dez. 2007.

SEN, Amartya. Desenvolvimento Como Liberdade. São Paulo: Companhia das Letras, 2000.

SEN, Amartya; KLIKSBERG, Bernardo. Primero la Gente. Barcelona: Ediciones Deusto, 2007.

TRIBUNAL DE CONTAS DO ESTADO DO RIO GRANDE DO SUL. Consultas relativas à execução da despesa orçamentária dos Poderes e/ou Órgãos da esfera municipal. 2009. Disponível em: <http://www2.tce.rs.gov.br/portal/page/portal/tcers/>. Acesso em: 09 jan. 2009. 